\title{
Unusual severe case of hemolytic uremic syndrome due to Shiga toxin 2d-producing $E$. coli O80:H2
}

\author{
Kioa L. Wijnsma ${ }^{1}$ - Anne M. Schijvens ${ }^{1}$ - John W. A. Rossen ${ }^{2}$ • \\ A. M. D. (Mirjam) Kooistra-Smid ${ }^{3} \cdot$ Michiel F. Schreuder $^{1}$ • Nicole C. A. J. van de Kar ${ }^{1}$
}

Received: 9 January 2017 / Accepted: 6 March 2017 /Published online: 25 March 2017

(C) The Author(s) 2017. This article is published with open access at Springerlink.com

\begin{abstract}
Background Hemolytic uremic syndrome (HUS) is one of the most common causes of acute renal failure in children, with the majority of cases caused by an infection with Shiga toxinproducing Escherichia coli (STEC). Whereas O157 is still the predominant STEC serotype, non-O157 serotypes are increasingly associated with STEC-HUS. However, little is known about this emerging and highly diverse group of non-O157 serotypes. With supportive therapy, STEC-HUS is often selflimiting, with occurrence of chronic sequelae in just a small proportion of patients.

Case diagnosis/treatment In this case report, we describe a 16-month-old boy with a highly severe and atypical presentation of STEC-HUS. Despite the presentation with multi-organ failure and extensive involvement of central nervous system due to extensive thrombotic microangiopathy (suggestive of atypical HUS), fecal diagnostics revealed an infection with the rare serotype: shiga toxin 2d-producing STEC O80:H2.
\end{abstract}

Kioa L. Wijnsma and Anne M. Schijvens equally contributed to this work.

Kioa L. Wijnsma

kioa.wijnsma@radboudumc.nl

1 Department of Paediatric Nephrology, Radboud University Medical Center, Amalia Children's Hospital, PO Box 9101, 6500 HB Nijmegen, The Netherlands

2 Department of Medical Microbiology, University of Groningen, University Medical Center Groningen, Hanzeplein 1, 9713 GZ Groningen, The Netherlands

3 Department of Medical Microbiology, Certe Laboratory for Infectious Diseases, PO Box 909, 9700

AX Groningen, The Netherlands
Conclusions This report underlines the importance of STEC diagnostic tests in all children with HUS, including those with an atypical presentation, and emphasizes the importance of molecular and serotyping assays to estimate the virulence of an STEC strain.

Keywords Hemolytic uremic syndrome - STEC-HUS · Serotype O80:H2

\section{Introduction}

Hemolytic uremic syndrome (HUS) is the most common cause of acute renal failure in children and is diagnosed when the features of hemolytic anemia and thrombocytopenia are present simultaneously [1]. In over $90 \%$ of pediatric cases, HUS follows a gastro-intestinal infection with Shiga toxinproducing Escherichia coli (STEC), previously known by the name of post-diarrheal or typical HUS, because of its main characteristic of (bloody) diarrhea [1]. Whereas O157 is still the predominant STEC serotype, non-O157 serotypes are increasingly associated with STEC-HUS [2]. However, in contrast to STEC O157, little is known about this emerging and highly diverse group of non-O157 serotypes. Thrombotic microangiopathy (TMA) causing HUS predominantly affects the renal vasculature. Nevertheless, especially in non-O157 STEC serotypes, extra renal involvement such as central nervous system involvement is described [3]. If symptomatic treatment is started in time, the recovery of STEC-HUS is often spontaneously with minimal chronic sequelae [4].

Here we present a case of a 16-month-old boy with an unusual presentation and rare STEC serotype resulting in a very severe course of STEC-HUS. 


\section{Case report}

A previously healthy 16-month-old boy presented at the emergency department of a general hospital with convulsions and impaired consciousness. He had a 2-day history of coughing, vomiting, and lethargy, without signs of fever. Three months prior, he had a period of non-bloody diarrhea for over a week after visiting a biological farmer. A detailed medical history of the patient and family revealed no ingestion of unpasteurized milk or cheese nor a visit to a foreign country. On physical examination he exhibited fluctuating levels of alertness. His respiratory rate was $29 / \mathrm{min}$ with oxygen saturation of $97 \%$. Body temperature $\left(36.4{ }^{\circ} \mathrm{C}\right)$ and blood pressure were normal $(98 / 60 \mathrm{mmHg}$ ) with mildly elevated pulse rate (138 beats per minute). Examination of the heart, lungs, and abdomen was unremarkable. Skin examination revealed a pale-looking patient with petechiae at lower limbs.

Based on clinical suspicion of meningitis or nonconvulsive status epilepticus, ceftriaxone and midazolam were administered and the patient was transferred to our hospital. Initial laboratory evaluation showed hyperglycemia and the triad of HUS (Table 1). In the first hours, consciousness further decreased and the patient was transferred to the pediatric intensive care unit (ICU), where peritoneal dialysis was initiated due to persistent anuria. Blood and feces samples to determine the presence of an STEC infection were obtained. Blood cultures were performed repeatedly and remained negative during admission. Thrombotic thrombocytopenic purpura (TTP) was excluded with a normal ADAMTS13 activity (Table 1). Atypical HUS (aHUS), caused by complement dysregulation, was considered because of severity of the presentation, mainly neurological presentation, no recent history of (bloody) diarrhea, and young age of the patient. Consequently, the patient received $600 \mathrm{mg}$ of eculizumab. Later incoming results of additional complement and DNA diagnostics showed no abnormalities (Table 1).

The following day, fecal diagnostics revealed an STEC infection, indicating STEC-HUS; real-time polymerase chain reaction (PCR) was positive for Shiga toxin 2 (Stx2) and attaching and effacing (eae) genes. In addition, molecular serotyping using whole genome sequencing revealed the rare STEC serotype O80:H2, which contained the Stx2d gene and the rarely in human seen eae $\xi$ gene variant (Table 1) [5].

In the course of admission, the patient developed multiple signs of severe, extra renal manifestations of TMA. Due to the severe neurological symptoms, with convulsions and decreased consciousness, brain magnetic resonance imaging (MRI) was performed, showing diffusion restriction of the deep white matter (Table 1).

On day four of admission, the patient was resuscitated twice due to post-intubation hypotension and bradycardia, with rapid recovery of cardiac output. Cardiac biomarkers were elevated, and retrospectively elevated troponin $\mathrm{T}$ levels and creatine kinase were already present. Echocardiogram revealed a mildly dilated and dysfunctional left ventricle. Eventually, a follow-up demonstrated a significant improvement in cardiac biomarkers and function.

Pancreas involvement was noticed based on a gradual rise in serum glucose and elevation of serum amylase and triglyceride concentrations without clinical signs of pancreatitis. Insulin treatment was needed for 2 weeks.

After 2 weeks, jaundice was observed in combination with elevated bilirubin levels, without signs of ongoing hemolysis. Progressive elevation of transaminases was measured, with normal levels of clotting factors but low serum albumin (Table 1). Liver biopsy showed extensive signs of cholestasis without microthrombi, most likely due to sludging or drugrelated effects (Fig. 1).

Eventually, our patient was hospitalized for over 3 months. Only minimal signs of neurological improvement were observed and over time the patient developed spastic dystonia. Furthermore, he exhibited persistently decreased levels of consciousness with frequent periods of severe agitation. The patient remained anuric for which dialysis was continued. Nine months after initial presentation, the patient died due to peritoneal and hemodialysis failure combined with progressive liver failure and further neurological impairment.

\section{Discussion}

In this report, we describe a 16-month-old boy with an unusual, severe presentation and course of STEC-HUS due to the rare Stx2d-producing E. coli $\mathrm{O} 80: \mathrm{H} 2$. STEC-HUS is a common cause of HUS in childhood and in more than half of the cases results from an STEC infection with serotype O157. However, non-O157 serotypes are increasingly associated with HUS in recent years, most likely due to improvement of diagnostics $[1,2]$. Usually, the majority of STEC-HUS resolves with no or minimal chronic sequelae.

STEC infection with serotype O80:H2 resulting in HUS was rarely described up to recently [2, 6-8]. To our knowledge, up till now, this serotype was only found in patients with HUS in France and this report is the first describing a case in the Netherlands. In addition, one study from Spain already described the finding of this serotype in cattle over 10 years ago. Interesting to note is that there is no direct geographic connection between the different areas. Hence, the source of the O80 serotype remains of unknown origin [8].

STEC strains can produce different shiga toxins, respectively $S t x 1$ and $S t x 2$. Within these genotypes, especially the $S t x 2$ gene, there is a wide variety of Stx subtypes, such as $S t x 2 d$ which we describe in this Case report [9]. Moreover, the Stx2d gene is known to cause a more severe course of disease. This together with the rare eae $\xi$ and the plasmid of the O80:H2 STEC, which showed high resemblance with the previous 
Table 1 Multi-organ involvement

Test At admission Most abnormal value At discharge Normal value

or range

Differential diagnosis

\begin{tabular}{|c|c|c|c|c|c|}
\hline & Blood culture & Negative & & Negative & \\
\hline$T T P$ & ADAMTS13 activity (\%) & $91 \%$ & & & $>65 \%$ \\
\hline \multirow[t]{15}{*}{ STEC-HUS } & Serology & & & & \\
\hline & $\mathrm{O} 157 \mathrm{IgM} / \mathrm{G} / \mathrm{A}$ & Negative & & & \\
\hline & $\mathrm{O} 26 \mathrm{IgM} / \mathrm{G} / \mathrm{A}$ & Negative & & & \\
\hline & PCR Stxl gene & Negative & & Negative & \\
\hline & Stx2 gene & Positive & & Negative & \\
\hline & eae gene & Positive & & Negative & \\
\hline & WGS Serotype & $\mathrm{O} 80: \mathrm{H} 2$ & & & \\
\hline & Isolate & Stx2d, eae $\xi$ variant & & & \\
\hline & Sequence type & ST301 & & & \\
\hline & Virulence factors & & & & \\
\hline & Stxlgene & Negative & & & \\
\hline & Stx2gene & Positive & & & \\
\hline & eae & Positive & & & \\
\hline & $\operatorname{agg} R$ & Negative & & & \\
\hline & aatA & Negative & & & \\
\hline \multirow[t]{14}{*}{ aHUS } & Complement & & & & \\
\hline & $\mathrm{C} 3(\mathrm{mg} / \mathrm{l})$ & 874 & NA & NA & $900-1800$ \\
\hline & $\mathrm{C} 4(\mathrm{mg} / \mathrm{l})$ & 71 & NA & NA & $150-400$ \\
\hline & Anti factor $\mathrm{H}$ autoantibodies & Negative & & & \\
\hline & DNA analysis & & & & \\
\hline & Factor $H$ & No pathogenic variation & & & \\
\hline & Factor I & No pathogenic variation & & & \\
\hline & Factor B & No pathogenic variation & & & \\
\hline & $C 3$ & No pathogenic variation & & & \\
\hline & $M C P$ & No pathogenic variation & & & \\
\hline & CFHR 1-5 & No pathogenic variation & & & \\
\hline & $D G K E$ & No pathogenic variation & & & \\
\hline & $T H B D$ & No pathogenic variation & & & \\
\hline & MLPA Factor H operon & No aberrations & & & \\
\hline \multirow[t]{6}{*}{ Hematological } & Hemoglobin $(\mathrm{mmol} / \mathrm{l})$ & 4.5 & 3.3 & 7.3 & $6.8-8.6$ \\
\hline & Platelet count $\left(\times 10^{9} / 1\right)$ & 22 & 18 & 872 & $210-430$ \\
\hline & WBC count $\left(\times 10^{9} / 1\right)$ & 15.5 & 29.0 & 12.9 & $5.0-17.0$ \\
\hline & Schizocytes (\%) & $>5$ & $>5$ & NA & $<0,5$ \\
\hline & Haptoglobin $(g / 1)$ & Hemolytic & Hemolytic & $1.85^{\mathrm{a}}$ & $0.3-1.6$ \\
\hline & LDH (U/1) & 2285 & 6521 & 908 & $<250$ \\
\hline \multirow[t]{3}{*}{ Kidney } & Creatinine $(\mu \mathrm{mol} / \mathrm{l})$ & 167 & 444 (PD) & 470 (PD) & $15-45$ \\
\hline & $\mathrm{eGFR}\left(\mathrm{ml} / \mathrm{min} / 1.73 \mathrm{~m}^{2}\right)$ & 17 & anuria & anuria & $80-120$ \\
\hline & BUN (mmol/l) & 43.9 & 44.2 & 22.4 & $2.5-7.0$ \\
\hline \multirow[t]{2}{*}{ Brain } & MRI & $\begin{array}{l}\text { Diffusion restriction of the } \\
\text { deep white matter } \\
\text { consistent with metabolic } \\
\text { encephalopathy }\end{array}$ & NA & NA & \\
\hline & EEG & No epileptic activity & NA & NA & \\
\hline \multirow[t]{3}{*}{ Heart } & CK (U/1) & 2743 & 8390 & $139^{\mathrm{a}}$ & $<170$ \\
\hline & Ntpro-BNP (pg/ml) & NA & $>180,000$ & NA & $<320$ \\
\hline & Troponin T levels (ng/l) & 557 & 23,444 & $508^{\mathrm{a}}$ & $<14$ \\
\hline
\end{tabular}


Table 1 (continued)

\begin{tabular}{|c|c|c|c|c|c|}
\hline & Test & At admission & Most abnormal value & At discharge & $\begin{array}{l}\text { Normal value } \\
\text { or range }\end{array}$ \\
\hline & Echo & NA & $\begin{array}{l}\text { Left ventricular } \\
\text { dysfunction }\end{array}$ & $\begin{array}{l}\text { Normal left } \\
\text { ventricular function }^{\mathrm{a}}\end{array}$ & \\
\hline \multirow[t]{3}{*}{ Pancreas } & Amylase (U/l) & NA & 1933 & $42^{\mathrm{a}}$ & $<105$ \\
\hline & Glucose (mmol/1) & 9.9 & 30.7 & 6.2 & $4.0-5.6$ \\
\hline & Triglycerides (mmol/1) & NA & 14.17 & 4.92 & $0.8-2.0$ \\
\hline \multirow[t]{7}{*}{ Liver } & AST (U/l) & 163 & 1020 & 114 & $<35$ \\
\hline & $\operatorname{ALT}(\mathrm{U} / \mathrm{l})$ & 62 & 480 & 144 & $<45$ \\
\hline & Gamma-GT (U/l) & 6 & 1810 & 824 & $<55$ \\
\hline & Alkaline phosphatase (U/l) & 205 & 1529 & 401 & $<115$ \\
\hline & Direct bilirubin $(\mu \mathrm{mol} / \mathrm{l})$ & 4 & 326 & 35 & $<5$ \\
\hline & Ultrasound & & $\begin{array}{l}\text { Edema around and } \\
\text { sludge inside gallbladder }\end{array}$ & & \\
\hline & Biopsy & & Cholestasis & & \\
\hline
\end{tabular}

aatA necessary for translocation of dispersin (Aap), ADAMTS13 a disintegrin and metalloproteinase with a thrombospondin type 1 motif, member 13, $a g g R$ transcriptional regulator aggR, $a H U S$ atypical hemolytic uremic syndrome, $A L T$ alanine transaminase, $A S T$ aspartate transaminase, $B U N$ blood urea nitrogen, $C F H R$ complement factor H-related proteins, $C K$ creatine kinase, $D G K E$ diacylglycerol kinase epsilon, eae E. coli attachment effacement gene (intimin), $E E G$ electroencephalogram, eGFR estimated glomerular filtration rate based on Schwartz estimation with k-value of 36.5, gammaGT gammaglutamyl transferase, $I g A$ immunoglobulin A, $I g G$ immunoglobulin $\mathrm{G}$, $I g M$ immunoglobulin $\mathrm{M}, L D H$ lactate dehydrogenase, $M C P$ membrane cofactor protein, $M L P A$ multiplex ligation-dependent probe amplification, $M R I$ magnetic resonance imaging, $N A$ not available, $N$ tpro- $B N P \mathrm{~N}$-terminal of the prohormone brain natriuretic peptide, $P C R$ polymerase chain reaction, $P D$ peritoneal dialysis, STEC Shiga toxin-producing Escherichia coli, Stx1 Shiga toxin 1, Stx2 Shiga toxin 2, THBD thrombomodulin, TTP thrombotic thrombocytopenic purpura, $W B C$ white blood cell count, WGS whole genome sequencing

${ }^{\mathrm{a}}$ Two months after presentation

described plasmid associated with extra intestinal virulence, resulted in an increased association with HUS [8]. Only recently, Soysal et al. described the STEC serotype O80 as a new therapeutic challenge in patients with STEC-HUS due to its capacity to cause a bacteremia [8]. Furthermore, Espié et al. described an outbreak of STEC serotypes O26 and O80 coinfection related to unpasteurized cheese [6]. However, our patient had no bacteremia and no indication of co-infection, tested with both fecal diagnostics and serological antibody assays against both $\mathrm{O} 157$ and $\mathrm{O} 26$ lipopolysaccharide (Table 1).

Mariani-Kurkdjian et al. described the case of an adult male with a severe episode of HUS caused by STEC O80:H2 containing both $S t x 2 \mathrm{~d}$ and the rare eae $\xi$ variant like the strain described above [7]. Similar to our case, the adult male patient presented with afebrile convulsions followed by coma and, after a few weeks, he developed bacteremia. This raised the question if the O80 serotype may not be cleared rapidly, in contrast to most other serotypes. Such a slow clearance would make it more likely that the STEC found in our patient could be the consequence of the gastro-intestinal infection three months prior to presentation $[8,10]$.

Nowadays, in the majority of laboratories, STEC diagnostics comprises PCR, culture, and/or enzyme immune-assays. Obviously, these approaches could have missed the identification of the $\mathrm{O} 80: \mathrm{H} 2$ strain. Using additional molecular and serotyping assays allows the detection of virulence factors and typing of the
Stx genes, both important to estimate the virulence of the strain. Such additional diagnostic tests are relevant both for individual patients as for public health to monitor new or rare serotypes that cause severe HUS and emerge into the population [9].

It can be challenging to clinically differentiate between STEC-HUS and aHUS due to similarity of symptoms. Similar to our patient, in 6-10\% of the children with STECHUS there is no (bloody) diarrhea, whereas aHUS is preceded by diarrhea in $25 \%$ of cases [11]. Since aHUS is merely a

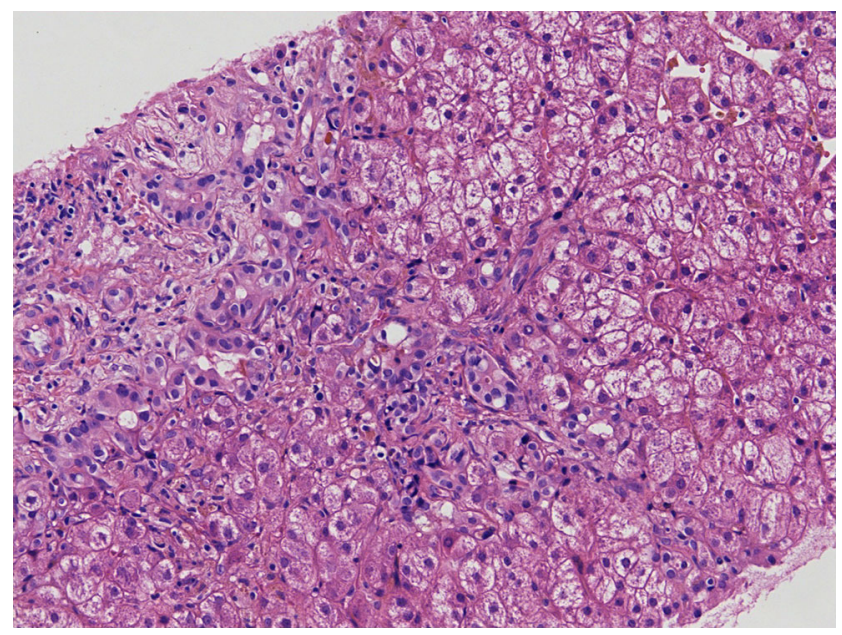

Fig. 1 Light microscopy on the liver biopsy (with hematoxylin and eosin staining) revealed hepatocyte swelling and extensive signs of cholestasis 
diagnosis per exclusionem, it is essential to prove the absence of an STEC infection [1, 12]. Even in cases without (bloody) diarrhea and atypical presentations such as young age of the patient, it is highly recommended to perform both fecal and serological diagnostics in every HUS patient to exclude STEC-HUS [12].

The treatment of STEC-HUS is merely symptomatic. A topic of discussion remains the use of antibiotics to eradicate STEC infection. Increased transcription, production, and release of shiga toxins, possibly aggravating HUS, can be induced by antibiotics [13]. Soysal et al. studied in vitro effects of different antibiotics on Stx production. Ceftriaxone, which our patient received at presentation, seems to have no effect on Stx production [8]. Another controversial topic in patients with STEC-HUS is the use of eculizumab. Eculizumab, a monoclonal antibody directed against complement $\mathrm{C} 5$, is nowadays the standard treatment in patients with aHUS [14]. Some case series, among others Pape et al., reported better outcome of STEC-HUS after eculizumab administration, particularly in neurologically affected STEC-HUS patients [3, 15]. However, Pape et al. also described the use of eculizumab in patients with multi-organ failure, where it seems to be associated with a less favorable outcome [15]. Well-designed and well-powered randomized controlled trials are needed to shed light on the effect of eculizumab in STEC-HUS.

Extra-renal manifestations of TMA are not uncommon in HUS. In $25 \%$ of HUS cases neurological involvement is noted, other organs are affected less frequently [1, 3]. Although severe multi-organ failure and especially liver failure is rarely described in STEC-HUS, the highly severe disease presentation in our patient could partially be explained by the (extraintestinal) virulence factors of this O80 strain. However, in our patient, jaundice and liver failure evolved 2 weeks after one dose of eculizumab possibly indicating hepatotoxicity. This was recently described in five pediatric aHUS patients [16]. Transient liver enzyme derangement was noticed in these children 10-29 days after the first dose of eculizumab with spontaneous resolution. The time pattern in our patient, as described above, cannot rule out the hypothesis that administration of eculizumab could have contributed to liver failure in our patient.

In conclusion, we describe a severe case of STEC-HUS caused by an unusual Stx2d-producing STEC O80:H2. This resulted in an unusual and severe disease course, complicated by multi-organ failure and central nervous system involvement. This case emphasizes the importance of molecular and serotyping assays to estimate the virulence of an STEC strain.

\section{Compliance with ethical standards}

Conflict of interest All the authors have indicated they have no potential conflicts of interest to disclose.
Financial disclosure All authors have indicated they have no financial relationships relevant to this article to disclose.

Funding source No external funding for this manuscript

Open Access This article is distributed under the terms of the Creative Commons Attribution 4.0 International License (http:// creativecommons.org/licenses/by/4.0/), which permits unrestricted use, distribution, and reproduction in any medium, provided you give appropriate credit to the original author(s) and the source, provide a link to the Creative Commons license, and indicate if changes were made.

\section{References}

1. Mele C, Remuzzi G, Noris M (2014) Hemolytic uremic syndrome. Semin Immunopathol 36:399-420

2. Espie E, Grimont F, Mariani-Kurkdjian P, Bouvet P, Haeghebaert S, Filliol I, Loirat C, Decludt B, Minh NN, Vaillant V, de Valk H (2008) Surveillance of hemolytic uremic syndrome in children less than 15 years of age, a system to monitor O157 and non-O157 Shiga toxin-producing Escherichia coli infections in France, 1996-2006. Pediatr Infect Dis J 27:595-601

3. Trachtman H, Austin C, Lewinski M, Stahl RA (2012) Renal and neurological involvement in typical Shiga toxin-associated HUS. Nat Rev Nephrol 8:658-669

4. Garg AX, Suri RS, Barrowman N, Rehman F, Matsell D, RosasArellano MP, Salvadori M, Haynes RB, Clark WF (2003) Longterm renal prognosis of diarrhea-associated hemolytic uremic syndrome: a systematic review, meta-analysis, and meta-regression. JAMA 290:1360-1370

5. Ferdous M, Zhou K, de Boer RF, Friedrich AW, Kooistra-Smid AM, Rossen JW (2015) Comprehensive characterization of Escherichia coli O104:H4 isolated from patients in the Netherlands. Front Microbiol 6:1348

6. Espie E, Mariani-Kurkdjian P, Grimont F, Pihier N, Vaillant V, Francart S, Capek I, de Valk H, Vernozy-Rozand C (2006) Shiga toxin-producing Escherichia coli $\mathrm{O} 26$ infection and unpasteurised cows cheese. Abstract presented of the 6th International Symposium on Shigatoxin (verocytotoxin)-Producing Escherichia coli Infections. Melbourne, Australia; October 30-November 1, 2006

7. Mariani-Kurkdjian P, Lemaitre C, Bidet P, Perez D, Boggini L, Kwon T, Bonacorsi S (2014) Haemolytic-uraemic syndrome with bacteraemia caused by a new hybrid Escherichia coli pathotype. New Microbes New Infect 2:127-131

8. Soysal N, Mariani-Kurkdjian P, Smail Y, Liguori S, Gouali M, Loukiadis E, Fach P, Bruyand M, Blanco J, Bidet P, Bonacorsi S (2016) Enterohemorrhagic Escherichia coli Hybrid Pathotype O80: $\mathrm{H} 2$ as a New Therapeutic Challenge. Emerg Infect Dis 22:16041612

9. de Boer RF, Ferdous M, Ott A, Scheper HR, Wisselink GJ, Heck ME, Rossen JW, Kooistra-Smid AM (2015) Assessing the public health risk of Shiga toxin-producing Escherichia coli by use of a rapid diagnostic screening algorithm. J Clin Microbiol 53:15881598

10. Bielaszewska M, Friedrich AW, Aldick T, Schurk-Bulgrin R, Karch $\mathrm{H}$ (2006) Shiga toxin activatable by intestinal mucus in Escherichia coli isolated from humans: predictor for a severe clinical outcome. Clin Infect Dis 43:1160-1167

11. Geerdink LM, Westra D, van Wijk JA, Dorresteijn EM, Lilien MR, Davin JC, Komhoff M, Van Hoeck K, van der Vlugt A, van den Heuvel LP, van de Kar NC (2012) Atypical hemolytic uremic 
syndrome in children: complement mutations and clinical characteristics. Pediatr Nephrol 27:1283-1291

12. Wijnsma KL, van Bommel SA, van der Velden $\mathrm{T}$, Volokhina $\mathrm{E}$, Schreuder MF, van den Heuvel LP, van de Kar NC (2016) Fecal diagnostics in combination with serology: best test to establish STEC-HUS. Pediatr Nephrol 31:2163-2170

13. Agger M, Scheutz F, Villumsen S, Molbak K, Petersen AM (2015) Antibiotic treatment of verocytotoxin-producing Escherichia coli (VTEC) infection: a systematic review and a proposal. J Antimicrob Chemother 70:2440-2446
14. Legendre CM, Licht C, Loirat C (2013) Eculizumab in atypical hemolytic-uremic syndrome. N Engl J Med 369:1379-1380

15. Pape L, Hartmann H, Bange FC, Suerbaum S, Bueltmann E, Ahlenstiel-Grunow T (2015) Eculizumab in typical hemolytic uremic syndrome (HUS) with neurological involvement. Medicine (Baltimore) 94, e1000

16. Hayes W, Tschumi S, Ling SC, Feber J, Kirschfink M, Licht C (2015) Eculizumab hepatotoxicity in pediatric aHUS. Pediatr Nephrol 30:775-781 